\title{
Reflexiones y visiones sobre la antropologia social en el México contemporáneo desde una mirada descolonial ${ }^{1}$
}

\author{
Verónica Renata López Nájera ${ }^{2}$ \\ Universidad Nacional Autónoma de México, México D.F., México ${ }^{3}$ \\ Universidad Iberoamericana ${ }^{4}$ \\ veronicarenat@gmail.com \\ Recibido: 15 de julio de 2013 \\ Aprobado: 24 de septiembre de 2013
}

Este artículo es el resultado de las primeras reflexiones sobre el tema de la antropologia social en México desde una mirada descolonial que realicé gracias a una beca para Estancia Posdoctoral, otorgada por el CONACYT, en el posgrado de Antropología Social de la Universidad Iberoamericana, ciudad de México. Agradezco a ambas instituciones las facilidades brindadas para la realización de la estancia.

2 Doctora en Estudios Latinoamericanos de la Universidad Nacional Autónoma de México.

3 Profesora de asignatura de la Facultad de Filosofia y Letras-UNAM.

4 Estancia Posdoctoral en el Posgrado de Antropologia Social, gracias a una beca otorgada por el CONACYT. 


\title{
Reflexiones y visiones sobre la antropologia social desde una mirada descolonial en México contemporáneo
}

\section{Resumen}

En este artículo reflexiono sobre el desarrollo de la antropología mexicana durante las últimas décadas, especialmente a partir de la publicación del texto De eso que llaman antropología mexicana (Warman, Nolasco, Bonfil, Olivera y Valencia, 1970), ya que considero que dicha publicación representa un giro en la práctica antropológica al presentar un acercamiento mucho más militante y activo, a la vez de reconocer una dimensión colonial en su configuración como disciplina. Me interesa evidenciar cuáles fueron las transformaciones de la antropología social en México a partir de esa década y cuál ha sido la presencia del debate poscolonial en la disciplina. Analizar asimismo si se ha generado una mirada critica y descolonial desde la cual se cuestionan las formas en que se representa a lo indígena como alteridad, contrastando así la influencia de la política indigenista del Estado mexicano posrevolucionario que tuvo vigencia hasta finales de la década de 1970. Por último, señalo las dos vertientes de la antropología mexicana que considero que han formulado una lectura cercana al debate poscolonial, aunque no necesariamente se reconozcan como parte de esa perspectiva.

Palabras clave: Antropología social en México, Alteridad y colonialismo, Indigenismo y descolonización. Palabras clave descriptores: Antropología social, Indigenismo, Descolonización, México.

\section{Reflections and Visions of Social Anthropology in the Contemporary Mexico from a De-Colonial Approach}

\begin{abstract}
This article presents a reflection about the development of Mexican anthropology in recent decades, especially since the publication of the text De eso que llaman antropología mexicana (Warman, Nolasco, Bonfil Olivera, \& Valencia, 1970). II consider that this publication represents a shift in the anthropological practice as it presents a much more militant and active approach, as well as a recognition of the colonial dimension in its configuration as a discipline. I am interested in demonstrating what the changes in social anthropology in Mexico were from that decade on, and what has been the presence of postcolonial discussion in the discipline. I also analyze whether it has generated a critical and de-colonial view from which the ways in which the indigenous is represented as otherness is questioned, contrasting in this way the influence of the post-revolutionary Mexican indigenous policy that was valid until the end of the 1970's. Finally, I point out the two sides of Mexican anthropology that I consider to have made a reading close to the postcolonial debate, although they are not necessarily recognized as part of that perspective.
\end{abstract}

Keywords: Social Anthropology in Mexico, Otherness, Colonialism, De-Colonization, Indigenism. Key words plus: Social Anthropology, Indigenity, Descolonization, Mexico.

\section{Reflexões e visões sobre a antropologia social no México contemporâneo desde um olhar descolonial}

\section{Resumo}

Neste artigo reflito sobre o desenvolvimento da antropologia mexicana durante as últimas décadas, especialmente a partir da publicação do texto De eso que llaman antropología mexicana (De isso que chamam de antropologia mexicana - Warman, Nolasco, Bonfil, Olivera y Valencia, 1970), pois considero que tal publicação representa uma viragem na prática antropológica ao apresentar um acercamento muito mais militante e ativo, à vez de reconhecer uma dimensão colonial em sua configuração como disciplina. Interessa-me evidenciar quais foram as transformações da antropologia social no México a partir dessa década e qual foi a presencia do debate pós-colonial na disciplina. Mesmo, analisar se foi gerado um olhar crítico e descolonial desde o qual são questionadas as formas em que é representado o indigena como alteridade, contrastando assim a influência da política indigenista do Estado mexicano pósrevolucionário que teve vigência até finais da década de 1970. Por fim, indico as duas vertentes da antropologia mexicana que acho formularam uma leitura próxima do debate pós-colonial, embora não necessariamente sejam reconhecidas como parte de essa perspectiva.

Palavras-chave: Antropologia social no México, Alteridade e colonialismo, Indigenismo e descolonização. Palavras-chave descritores: Antropologia Social, Indígena, A descolonização, México. 


\section{Introducción}

Me propongo realizar una breve reflexión acerca del desarrollo de la antropología mexicana en las últimas cuatro décadas, tratando de reconocer si a partir de la difusión de los estudios poscoloniales en el país y de las experiencias de descolonización, tanto en las ciencias sociales como en los procesos de movilización ${ }^{5}$ y transformación social en América Latina, esta disciplina ha modificado las formas en las que entiende, caracteriza y representa a lo indígena y -de ser así- en qué sentido.

Estimo importante esta reflexión ya que durante muchas décadas la antropología mexicana no consideró el problema del colonialismo y la racialización de la sociedad mexicana. El peso del discurso del mestizaje como proyecto nacional, que pretendía constituir una sociedad homogénea en torno a la idea del mestizaje racial y cultural se desmoronó a partir del levantamiento zapatista en 1994. Esta invisibilización histórica del problema racial en México, le confiere a la disciplina un registro que en algún sentido determinó su forma de acercarse al indígena. Visto como una otredad, el indígena fue incorporado como un objeto de estudio, como un problema de conocimiento, como un vestigio del pasado.

Por ello, la interrogante que articula este ensayo trata de reconocer si en los estudios antropológicos realizados en México en los últimos años, existe un diálogo con la perspectiva de crítica al colonialismo interno, la crítica poscolonial o con el giro decolonial ${ }^{6}$ y cómo podemos caracterizarla. Asimismo, de qué manera se ha resignificado la categoría de indigena en un contexto de modificaciones en el orden cognitivo, metodológico y de identificación de los sujetos. Cabe entonces preguntarse, ¿cuál es el papel que ha jugado la antropología en México como campo de estudio de la alteridad, la otredad y lo indígena? Considero

5 Pensamos en los casos de Bolivia y Ecuador como ejemplos de países que han experimentado procesos de descolonización.

6 Propongo que para el caso latinoamericano, existe una diferencia sustancial en la trayectoria que han seguido tanto el discurso poscolonial, el giro decolonial y la crítica al colonialismo interno. La primera es el desarrollo de la reflexión que se ha dado en los países que recién se descolonizaron en el siglo XX, como la India, África o algunas islas del Caribe. Para estos países, la pregunta por la construcción de la Nación moderna se constituye a partir de los problemas que se enfrentan tras el fin de la Segunda Guerra Mundial y las reconfiguraciones en el orden mundial que ello implica. Mientras que el giro decolonial es el lugar de enunciación del cual parte el grupo Modernidad-colonialidad para pensar la profundidad histórica de la colonialidad del poder en América Latina. Véase Walter D. Mignolo "El pensamiento decolonial: desprendimiento y apertura. Un Manifiesto" (2007). Mientras que la crítica al colonialismo interno proviene de las reflexiones que surgieron a mediados de la década de 1950 en la región en el momento de auge de la teoria del desarrollismo de la CEPAL y la teoria de la dependencia, en trabajos como los de Pablo González Casanova (2006) y Profundo (2005). Esta perspectiva de interpretación está aún por desarrollarse. 
que la antropología que se realiza en el país debe pasar por un ejercicio de revisión crítica de sus supuestos teórico-metodológicos, y de su pertinencia como campo de estudio,

Una descolonización de la antropología mexicana debe pasar por la revisión crítica del tema de la raza y de la invisibilización del sujeto indígena como sujeto con capacidad de acción social e histórica. Para ello, sería necesario cuestionar la idea de lo mestizo como condición que encubre, oculta y desconoce la condición indígena y con ello, reconocer en qué medida la antropología contribuyó y contribuye a promocionar esta separación que se perfila como ontológica; es decir, si realmente lo indígena puede ser pensado como una experiencia radicalmente distinta del ser mestizo o blanco, y en qué radicaría esa distinción.

\section{De eso que llaman antropología mexicana. Un texto de ruptura}

El desarrollo de la antropología en México durante el siglo XX respondió a un proyecto académico entretejido con la política nacional y las políticas públicas emanadas del Estado mexicano posrevolucionario, que implicaron como consecuencia un condicionamiento de las formas de conceptualizar y representar a lo indígena como un problema u obstáculo al desarrollo pleno ${ }^{7}$, en un contexto de desarrollo industrial modernizador que caracterizó a la década de 1950. Si bien se mantiene una constante en la forma de representar al indígena a lo largo del siglo XX, es hacia finales de la década de 1970 que se experimenta un primer momento, que podemos caracterizar como de relevo generacional, en el que un nutrido grupo de antropólogos sociales se dan a la tarea de hacer un primer corte de caja, un balance crítico de sus propios fundamentos como disciplina.

Para Andrés Medina (1976), historiador de la antropología mexicana, el indigena ha sido objeto de estudio en el país desde hace varios siglos; desde las crónicas escritas por los primeros historiadores cuando recién termina la conquista, escritos de navegantes y conquistadores, pasando por los primeros historiadores, geógrafos y sociólogos

\footnotetext{
Las teorias de la modernización y el cambio social en México, tuvieron fuerte impacto entre las décadas de 1950 y 1970. En resumen, proponian que el desarrollo económico, en ese contexto fomentado por el proyecto de industrialización y sustitución de importaciones, debía acompañarse de un intenso proceso de secularización de la sociedad, el cual implicaba el paso de las sociedades tradicionales a las sociedades plenamente modernas. Vease Gino Germani, Politica y sociedad en una época en transición: de la sociedad tradicional a la sociedad de masas (1971).
} 
del siglo XIX, pero que asume una forma concreta cuando la antropologia se configura formalmente como área o disciplina de estudio, es decir, cuando esta experimenta un proceso de institucionalización y sistematización propia, durante las primeras décadas del siglo XX.

Durante los regimenes posrevolucionarios que abarcaron desde el fin de la revolución mexicana en 1917 hasta la década de 1970, se “(...) conjuga la búsqueda de la conciencia nacional en las culturas indias y su aniquilación en nombre de la unidad nacional" (Medina, 1976, p. 223). En ese contexto, el indígena es representado de dos formas: como la expresión de un pasado glorioso "el indio poético y lejano" y otra en que el indígena es un eslabón inferior de nuestro proceso en marcha hacia el progreso y el desarrollo, el indio "tonto y próximo", como dice Andrés Medina (1976).

La politica indigenista va a caracterizar el periodo entre las décadas de 1940 y1970, durante el cual se propone incorporar al indígena a la Nación a partir de la modernización de su ser ancestral. Manuel Gamio, fundador de la corriente del indigenismo, propone la integración del indio a la Nación mexicana. Gamio propone que los indígenas conserven sus rasgos positivos, reconociendo que han sido históricamente explotados por su condición marginal, y a la vez eliminando los negativos, es decir, aquellos que representan una rémora a las posibilidades de la modernización social.

Modernizar al indígena se convierte en una necesidad para el desarrollo nacional. En este proceso la antropología juega un papel central ya que es la disciplina encargada de realizar estudios sobre su cultura, los cuales permiten conocer e interpretar a los indígenas. Esta perspectiva reconoce el desconocimiento histórico del indígena, lo cual implica un extrañamiento de su ser. Por ello, Bonfil Batalla (1995) dirá que la historia del indígena es una larga historia de equivocaciones que se corregirá con su integración a la Nación.

(...) deliberar el trasfondo del proyecto indigenista mexicano injertado en los programas de la Revolución Mexicana como parte del Estado, lo que dio origen a muchas contradicciones profundas. Por esta razón, muchos de los proyectos específicos presentados al gobierno nacional por los antropólogos, entraron en conflicto y contradicción con los políticos del sistema, lo que motivó que fracasaran y que una gran parte de nosotros los antropólogos nos enfrentáramos a los grupos de poder regional y nacional, generando una profunda 
crisis en las estructuras sociales confrontadas entre los pueblos indígenas con el Estado y la sociedad nacional. (Nahamad, 2011, pp. 1-2)

En este contexto, los antropólogos juegan un doble papel: de intérpretes del indígena y de administradores de las políticas estatales encaminadas a su incorporación a la Nación mexicana. Es justo frente a esta doble actuación que se discute la pertinencia y necesaria reformulación de la antropología.

De eso que llaman antropología mexicana (Warman et al., 1970) es un texto clave para conocer el estado de la antropología durante el siglo XX, ya que parte de un cuestionamiento fundamental. En el texto, publicado en 1970 en un contexto de alta politización social tras los cambios que ocurrieron en el país con el movimiento estudiantil del '68, antropólogos como Arturo Warman, Guillermo Bonfil Batalla y Mercedes Oliveira se proponen reflexionar, cada uno desde su perspectiva, los avatares de la disciplina, así como los retos a fututo. El centro del debate es la forma en que se ha conceptualizado al y lo indígena para su estudio. Todos los autores coinciden en que el origen de la antropología es consecuencia del carácter expansionista de Occidente. En México y desde la colonia, el indio ha sido un sujeto dominado, concebido como una anomalía porque se encuentra fuera de la historia. Desde el siglo XIX, durante el auge de las ideas liberales, el indio fue caracterizado como un problema al cual era necesario modernizar.

$\mathrm{El}$ artículo de Warman, que lleva por título "Todos santos y todos difuntos. Crítica histórica de la antropología mexicana" se propone realizar una revisión histórica de la antropología como "una cierta manera de enfrentar el fenómeno humano" (1970), que le permite rastrear las formas iniciales de conceptualización de lo indígena a partir de la conquista. Así, desde los evangelizadores, los propios indígenas como traductores e informantes, los criollos, ya avanzada la colonización; los liberales post- independentistas, los intelectuales pos-revolucionarios y los antropólogos profesionales ya a mediados del siglo XX, han conformado un campo de problematización en torno a lo indígena. Con distintas perspectivas y formas de acercamiento, con tensiones y contradicciones, la antropología se ha caracterizado por ver al indígena como otro, una alteridad que resulta un enigma en tiempos de modernización y progreso social.

Además, el autor señala el carácter colonial de la disciplina, su servidumbre a los poderes establecidos y su falta de autonomía 
y rigurosidad analítica. Es esta la casuística con que explica fenómenos complejos como el de la realidad indígena del país, "[...]así, el indigenismo, ámbito natural de la antropología mexicana, se ha convertido en su limitación." (Warman, 1970, p. 37).

El artículo de Bonfil Batalla "Del indigenismo de la revolución a la antropología crítica", centra la mirada en la antropología indigenista. El autor propone que es en el año 1910 cuando se empieza a formular una perspectiva antropológica de corte indigenista, que debe ser entendida en el contexto de la "[...]reforma agraria, la educación rural y el movimiento intelectual nacionalista, que alcanzó su expresión más cabal durante el cardenismo.” (Bonfil, 1970, p. 41). Para el autor, el indigenismo intenta desaparecer al indio a partir de su completa asimilación a la Nación y la pérdida de su identidad indígena, es decir "[...]el intento de extirpar la personalidad étnica del indio.”(Bonfil, 1970, p. 44).

Las comunidades indígenas, frente a esta política de integración, han recuperado y reforzado sus lazos comunitarios. Sin embargo, su cultura ha estado alienada desde la conquista. Para Bonfil, dadas las condiciones asimétricas en que el indígena se ha incorporado a la $\mathrm{Na}$ ción, solo el reconocimiento de su existencia y por ende de que México es una Nación pluricultural, podrá permitir en efecto, su incorporación desde una posición distinta (Bonfil, 1970, pp. 56-57).

En ese sentido, el papel de la antropología social consiste, siguiendo a Bonfil, en adquirir herramientas conceptuales, inexistentes en ese contexto, que le permitan comprender el funcionamiento de sociedades complejas y estratificadas como las nuestras. Su propuesta, así como la manera en que ubica el problema del indígena en México, se contrapone a las visiones dominantes de la época que seguían buscando soluciones al problema indígena desde la perspectiva de la alteridad, pero sin reconocer desde los supuestos teóricometodológicos desde los que se parte, esta condición de otredad que implicaba una cosificación del indígena.

El texto que venimos revisando se convirtió en centro de la discusión y motivó el desarrollo de una antropología más militante y activa. Para Nahmad, este texto inaugura un momento en el que se perfila una antropología crítica que más adelante formulará la "teoría de la descolonización interna como elemento clave para liquidar las relaciones interétnicas asimétricas"(Nahamad, 1978). La aceptación de un pluralismo étnico igualitario es premisa fundamental, señalaba Bonfil Batalla desde entonces, de una sociedad más justa (Bonfil, 1970). 


\section{Zapatismo y descolonización en la antropología mexicana}

A partir de la década de 1980, la antropología, al igual que el conjunto de las ciencias sociales, pasaron por un momento de reconsideración de sus supuestos, temas centrales, paradigmas y metodologías, que está dado en función de las modificaciones de su objeto de estudio. Si hay una característica singular de nuestros tiempos es la llamada eclosión de la diversidad, es decir, la supuesta aparición de nuevos sujetos.

Considero que más que la aparición de nuevos sujetos, estamos frente a un viraje de los fundamentos epistemológicos de las ciencias sociales, que nos permiten visibilizar temas y sujetos que habian sido considerados marginales o que habian permanecido invisibilizados hasta entonces, como lo es toda la cuestión indígena. Se puede mencionar la caracterización del campesino entre las décadas de 1930 y 1980 como un ejemplo de la manera en que se abordaba el estudio de un sujeto solo desde una de sus dimensiones: la económico-estructural. La cuestión identitaria y cultural es el resultado de una reflexión contemporánea. Esta diversidad invisibilizada implica un reto conceptual, particularmente para una disciplina cuyo objeto de conocimiento es la alteridad.

El cambio en la antropología que pretendo analizar, estuvo dado en dos sentidos: por un lado, la modificación o reconsideración de la categoría campesino como unidad representativa de lo indígena, y por el otro, el consecuente reconocimiento de la condición étnica y de la diversidad multicultural que conforman al país. Para la década de 1990 , estos dos sentidos fueron reconsiderados a la luz de procesos significativos que reforzaron este ejercicio de reflexión: la conmemoración de los 500 años del descubrimiento de América que derivó en intensos debates sobre si fuimos descubiertos o inventados, y por supuesto, el año del levantamiento zapatista, en 1994.

Es en esta misma década que los estudios poscoloniales comienzan a ser debatidos en América Latina, sin embargo, para el caso de México, solo hasta inicios del siglo XXI comienzan a tener cierta presencia, sobre todo los trabajos de la red Modernidad/Colonialidad ${ }^{8}$. Propongo la hipótesis de que este retraso en el desarrollo de la perspectiva se debe a dos razones: la primera, por el peso de la crisis del marxismo,

8 La red Modernidad/Colonialidad esta integrada por un grupo multidisciplinario de pensadores latinoamericanos que vienen trabajando en función de la propuesta de Aníbal Quijano sobre la Colonialidad del poder. 
especialmente con la caída del llamado socialismo realmente existente a inicios de la década de 1990, que no se vivió en México con la misma intensidad que en otros países del mundo, es decir, como un trastrocamiento profundo de ciertas concepciones y abordajes teóricometodológicos que habian guiado la reflexión a lo largo del siglo XX.

En México la crisis del marxismo coincidió con el levantamiento armado y la declaración de guerra del Ejercito Zapatista de Liberación Nacional, en 1994. Dicho levantamiento orientó la desazón, desesperanza y desconcierto que generó el derrumbe del bloque socialista hacia un nuevo escenario político, social y cultural, que repercutió en la teoría y en los campos de investigación de las diversas ciencias sociales en México. La antropología en ese sentido jugó un papel central. El histórico objeto de estudio de la antropología mexicana demostró su capacidad de organización, movilización y voz propia, lo cual invirtió en varios sentidos las formas en que la disciplina abordaba el estudio de las comunidades indigenas.

La segunda razón del retraso en el arribo del debate poscolonial a México, de índole más bien ideológico, se debió a que se le empató con el debate de la posmodernidad y se le incluyó en el mismo corpus teórico. Los estudios poscoloniales que son tan amplios en cuanto a espacios de producción y temas de reflexión, no pueden ser caracterizados como una teoria formal con un solo tema de reflexión. Al contrario, son una perspectiva de análisis con distintos lugares y tiempos de producción. Desde la escuela de Estudios Subalternos de la India, los estudios de la negritud en las Antillas y los Estados Unidos, el feminismo del Tercer Mundo y la teoría descolonial en Estados Unidos, la India y América Latina, por mencionar algunos 9

Al reconocer esta diversidad de posturas, el sentido que confiero a la descolonización en este artículo se refiere a la propuesta formulada por el sociólogo peruano Aníbal Quijano en función de superar la colonialidad del poder y del saber (Quijano, 1992; 2000). La colonialidad del poder es un patrón, una estructura de clasificación socio-racial que ordena y jerarquiza a las sociedades que fueron colonizadas. Es un patrón que atraviesa la larga historia de los pueblos colonizados y se expresa en el presente de distintas formas. Sin embargo, el eje que articula la jerarquización social es la raza, entendida como un constructo universal.

9 Véase por ejemplo el trabajo de Miguel Mellino, (2008) y para el caso latinoamericano, el trabajo de Karina Bidaseca, (2010). 
En el marco de la conmemoración de los 500 años, aparecen nuevas organizaciones indígenas que proponen la articulación con otras organizaciones sociales y luchas. A nivel regional, un amplio movimiento indígena comienza a demandar el reconocimiento de sus derechos y especificidades culturales. En esos años se aprueba en México la reforma al artículo $4^{\circ}$ de la Constitución que reconoce la composición pluricultural de la Nación (Castellanos, López \& Rivas,1992).

(...) el lugar de la población india en el conjunto histórico que constituye la Nación mexicana; y es más, la línea política dominante ha sido, hasta ahora, la de su exterminio, sea por su 'integración', por su "incorporación" a la totalidad nacional, como se ha denominado a los programas indigenistas, o por su sometimiento incondicional a las nuevas politicas 'bilingües y biculturales'. (Medina, 1987)

A pesar del reconocimiento constitucional de la composición pluricultural del Estado Mexicano, en el país el derecho a la autodeterminación de los pueblos indígenas es letra muerta, ya que no hay una verdadera descolonización del Estado, en el sentido de construir las bases que promuevan la equidad y el respeto a la autodeterminación indígena. Ejemplo de ello es el incumplimiento de los Acuerdos de San Andrés, que fueron el resultado de las mesas de negociación entre el gobierno federal y los zapatistas entre 1995 y 1996. En dichos acuerdos se establecía la necesidad de formular una nueva relación del Estado con las comunidades indígenas a partir del reconocimiento de los derechos de los pueblos indios, no solo a nivel individual sino como colectivos, en torno a cinco campos: derechos politicos, jurídicos, sociales, económicos y culturales (CEDOZ, 2013).

Sin embargo, las transformaciones que se hicieron a nivel constitucional y la reforma del Estado se mantuvieron en márgenes estrechos que impidieron el verdadero reconocimiento de la autonomía indígena. Aquí no trabajaré la historia del movimiento. Lo que me interesa es comentar los cambios significativos que se experimentaron en la forma en que se representa y conceptualiza al indígena.

Quizá el aporte más significativo del levantamiento zapatista sea la visibilización de las contradicciones de una Nación que se concibe como homogénea en torno al discurso del mestizaje cultural que durante todo el siglo XX fue política estatal. El Estado mexicano tuvo que reconocer -precisamente en el momento en que entraba en vigencia 
el Tratado de Libre Comercio de América del Norte (TLCAN) ${ }^{10}$ mediante el cual nos incorporábamos a la economia mundial- que ha sido y continúa siendo un Estado patriarcal, mestizo y pretendidamente homogéneo.

Tras el levantamiento zapatista se renovaron dos perspectivas de estudio de la antropología social mexicana: la antropología jurídica, encargada de pensar el problema de la autonomía indigena, entendida como autogobierno en el seno de una Nación con pretensiones monoétnicas. Y la vertiente de la antropología social que a partir de una diversa gama de estudios sobre los llamados usos y costumbres han intentado revisar las formas en las que las comunidades indigenas se configuran en función de la comunidad.

Mientras que el impacto del movimiento zapatista en la antropología mexicana es incuestionable, la perspectiva poscolonial permaneció invisibilizada y fue rechazada por su impronta posmoderna. Solo años más tarde comenzará a ser considerada como una vertiente que propone abordar el problema de lo indígena, el colonialismo interno, la raza y el Estado monocultural ${ }^{11}$.

En el siguiente apartado veremos cómo se ha dado este nuevo acercamiento y si, en alguna medida, dialoga con la perspectiva de la descolonización.

\section{¿Descolonización de la antropología o antropología de la descolonización?}

En un artículo publicado en 1976 J. Grigulevich se preguntaba por el futuro de la antropologia social. Señalaba entonces que la crisis por la que transitaba la disciplina era más de corte ideológico que metodológico o teórico. Desde entonces las contribuciones que se han hecho en ese

10 El Tratado de Libre Comercio de las Américas implicaba la liberalización y apertura económica en función del comercio con Estados Unidos y Canadá. El tratado era visto por sus promotores como la forma de integración a la economia del primer mundo, mientras que sus críticos han señalado que las condiciones desiguales de competencia sólo ahondarian más la brecha entre pobres y ricos, lo cual ha sido confirmado en los últimos años. Uno de los rubros más agresivos del tratado era el tema del campo y la comercialización de productos agrícolas.

11 En abril de 2013 organizamos las Primeras Jornadas de Reflexión: Decolonialismo, antropologia social e interculturalidad: diálogos criticos, en el Posgrado de Antropología Social de la Universidad Iberoamericana. De las más de 50 ponencias que recibimos, es interesante señalar que, si bien la mayoría no se encuentra familiarizada con el léxico poscolonial, sin embargo, los temas y enfoques de las ponencias se concentran en la búsqueda de pensar y representar lo indigena desde nuevas coordenadas reflexivas. 
sentido reflexivo han sido escasas para el caso mexicano. Algunos de los autores que han participado del debate son Esteban Krotz, Andrés Medina y Fernando León. Sin embargo, considero que el camino es aún largo y necesariamente implica una revisión profunda en tres dimensiones: la alteridad, la otredad y lo indígena, partiendo del reconocimiento de que:

(...) el sistema de las representaciones del indio en México no debe ser considerado jamás como del orden de un imaginario inofensivo y etéreo, fantasioso, sino que ordena y trabaja profundamente el cuerpo social produciendo violentos efectos sobre la identidad colectiva así como sobre las relaciones interindividuales. (Rozat, 2001, p. 12)

Como ya he mencionado anteriormente, en el caso de México la antropología madura como disciplina a través de una tensa relación entre las autoridades estatales y los intereses de conocimiento para la dominación: es el colonialismo en su versión neo-colonial. En México los primeros trabajos que comienzan a pensar desde una crítica al colonialismo interno surgen en la década de 1970 y son elaborados por Guillermo Bonfil Batalla (2005), Rodolfo Stavenhagen (1977) y Pablo González Casanova (2006). A pesar de la importancia del problema que plantean en su momento, la centralidad del marxismo en un contexto mundial de guerra fría y la proyección a nivel regional del ideal revolucionario, opacará el debate al considerar como premisa fundamental de la emancipación del campesino, la previa liberación del proletariado.

En ese contexto, Bonfil Batalla ya está pensando en la necesidad de poner en cuestión la univocidad de la Nación mestiza mexicana. En México profundo el autor plantea que existen dos Méxicos. Uno subsumido e invisibilizado y otro que se superpone y domina al anterior. Consciente de la profundidad estructural de la desigualdad y la marginación hacia los indígenas, propone una reconsideración del concepto mismo de lo indígena:

(...) indio es una categoría supraétnica que no denota ningún contenido específico de los grupos que abarca, sino una particular relación entre ellos y otros sectores del sistema social global del que los indios forman parte. La categoría de indio denota la condición de colonizado y hace referencia necesaria a la relación colonial. (Bonfil, 1972, p. 110) 
Desde esta reconsideración de lo indígena es posible situar el problema de la dominación en el marco de la historia colonial y neocolonial. Como propondrá Aníbal Quijano unos años después, la colonialidad es la cara oscura de la modernidad, por ello, es parte constitutiva y no una consecuencia posterior (Quijano, 1992). Cuando hablamos de modernización solo estamos situando un problema histórico en un presente que no reconoce las profundas estructuras de dominación que persisten desde la época colonial.

Algunas propuestas críticas al concepto de lo indígena en la actualidad, parten de cuestionar la consideración de la lengua como el parámetro para asignar pertenencia o identidad étnica. El hecho de la progresiva desaparición de hablantes de lenguas indígenas, información sobre todo obtenida a partir de los censos nacionales, se considera como un dato que señala la reducción poblacional de los grupos indigenas. Sin embargo, estudios recientes apuntan que el reconocimiento o sentido de identidad no puede ser pensado solamente en función de la lengua, sino en función de otros elementos, como las prácticas culturales o los llamados usos y costumbres, ya que el proyecto de Nación mestiza implicó en muchos casos el ocultamiento o negativa de transmisión de la lengua en función de la integración nacional. La política indigenista tuvo como eje la incorporación-integración del indio a la Nación a través de procesos de aculturación, sobre todo basados en el proyecto de educación monolingüe, por ello no es extraño que los grupos indígenas fueran abandonando progresivamente su lengua, ya sea negando su conocimiento o adoptando el castellano como primera lengua.

En esta primera línea de renovación de la antropología mexicana, se analiza la recuperación de la identidad y resignificación de las prácticas culturales como manifestaciones de pervivencia de lo indígena. Los trabajos que realizan Robichaux y Magazine (2007) en el México contemporáneo se proponen cuestionar estos esquemas de interpretación convencional que le confieren a lo indígena, desde modelos de representación formulados a partir de los diseños ideales del Estado-nación mestizo, una configuración en la que moderno, mestizo o urbano, ocultan más que explican, los verdaderos sentidos de su realidad socio-cultural.

Los estudios rurales y campesinos sirvieron como un campo de problematización que intentó explicar la situación del indígena como ente económico (campesino, productor) y no como ser cultural. Cuando se mencionaba en algunos casos la condición cultural como elemento 
explicativo, se lo hacía para representar al indígena como un ser atrasado y reacio a la modernización. El problema, mencionan los autores, se explica en parte por la concepción estrecha que se tiene de cultura en el momento (2007).

Para Robichaux y Magazine es interesante ver que en lugares tan cercanos al Distrito Federal como el valle de Texcoco ${ }^{12}$, pervivan en las prácticas sociales de los pueblos, elementos o formas de convivencia que refieren a los llamados usos y costumbres. Son grupos que se identifican como mestizos y no hablan la lengua, pero que en lo cotidiano se rigen por sus prácticas como la toma de decisiones en asamblea, las fiestas populares, las relaciones de parentesco, los cargos o mayordomías, por mencionar algunos ejemplos.

Lo anterior apunta uno de los primeros retos que debe enfrentar la antropología mexicana que se encarga del estudio de lo indígena: una revisión de los conceptos, categorias y concepciones de la historia que emplea para la problematización de lo indígena.

En la línea de investigaciones de la antropología jurídica que, como resultado del levantamiento zapatista, comenzaron a reflexionar sobre una nueva relación con el Estado y el reconocimiento de las comunidades indígenas, resaltan los trabajos de Aída Hernández, que además reflexiona desde una perspectiva feminista y descolonial (2012). En los trabajos de la antropóloga mexicana, existe una argumentación constante: las identidades étnicas o culturales son dinámicas, cambiantes y fluidas.

Concibo las identidades étnicas como construcciones sociales dentro de un marco histórico específico, en el que las etnias ocupan posiciones jerarquizadas dentro de una estructura determinada. (Hernández, 2012, p. 28)

Esta concepción de la identidad le permite reconocer las distintas formas, a veces incluso contradictorias y en tensión, que configuran las propias comunidades indigenas para, lejos de los esencialismos, establecer sus propios parámetros de reconocimiento, articulación comunitaria y solidaridad en los marcos de proyectos alternativos de modernidad.

12 Texcoco es una ciudad del Estado de México que se ubica en la zona metropolitana del Distrito Federal. 
Hernández retoma asimismo la teoría de la diáspora (Gilroy, 1993) que proviene de los estudios culturales y la negritud, para pensar aquellas culturas que si bien, sus origenes se vinculan a la herencia colonial, han experimentado procesos de desplazamientos, migración y desterritorialización que los llevan a cuestionar y resignificar sus identidades como indígenas.

Es a partir de este cuestionamiento de una representación esencialista de lo indígena, que las mujeres indígenas de distintas comunidades han llevado adelante procesos de transformación de sus prácticas culturales, poniendo en cuestión aquellas que las afectan o que reproducen el patriarcado.

En su trabajo más reciente (Hernández, 2012) la autora se propone: "acercarme a la diversidad de experiencias que están reconstituyendo el sentido de ser indígena kanjobal, chuj, mam, jacalteco, caqchikel o mochó" (Hernández, 2012, p. 47) en la frontera sur de México, partiendo de estos complejos procesos de reconstitución identitaria.

A partir de las ideas que propone Aída Hernández se recupera el debate de las modernidades alternativas que piensan lo indígena como expresión de una tensa contradicción entre lo tradicional y lo moderno. Estudios desde la llamada nueva antropología que se desarrolla a partir de la década de 1980 a nivel mundial, reconocen la necesidad de cuestionar la concepción de modernidad hegemónica como un universal abstracto e incorporar las concepciones que hablan sobre modernidades alternativas que provienen de otros campos disciplinares como la filosofia, los estudios culturales o la historiografia critica ${ }^{13}$.

Desde estas perspectivas, las formas de sociabilidad indígena representan experiencias particulares pero al mismo tiempo integrantes del desarrollo histórico de la modernidad. En ese sentido, propongo un diálogo que intente valorar y discutir la concepción de la modernidad y lo moderno para ubicar la situación de lo indígena. Silvia Rivera Cusicanqui (1993), socióloga boliviana, refiere que en su país lo indigena despliega un ejercicio de la modernidad que lo incorpora en la dinámica mundial y lo coloca con el resto de la humanidad en la misma trayectoria histórica de larga duración. La diferencia estaría relacionada con las condiciones específicas en que experimenta la condición moderna, tanto material como simbólica. Propone la cultura

13 Pienso por ejemplo en los trabajos de Michell Michell Rolph-Trouillot (2011), Bolivar Echeverría (1998). Rita Segato (2007) que desde distintas perspectivas y tradiciones disciplinarias, realizan entrecruces y diálogos que les permiten situar el problema de las modernidades alternativas. 
cheje como un mestizaje abigarrado que genera espacios de tensión entre la matriz indígena y la matriz liberal.

Otros ejemplos que podrían orientar la discusión son los trabajos que Carlos Lenkersdorf (2002) realizó con las comunidades tojolabales que habitan en Chiapas, con el aporte significativo de conceptualizar el nosotros comunitario, o los trabajos de Sylvia Marcos (2011) sobre epistemologías tradicionales que formula en su experiencia con los zapatistas, particularmente con las mujeres indigenas que forman parte de las comunidades de base.

Uno de los giros principales del nuevo momento del indigenismo se caracteriza porque la cuestión étnica comienza a ser vista como un problema de carácter teórico y político (Medina, 1987). El neo-indigenismo se caracteriza por la forma de abordar el problema del indio por parte del Estado mexicano, en el contexto neoliberal. Con la desaparición del Instituto Nacional Indigenista en 2003 y la creación de la Comisión Nacional para el Desarrollo de los Pueblos Indígenas, se enfrenta un momento de recambio de política institucional que no necesariamente significa la modificación de las formas en las que el Estado ha pensado y piensa al indígena. Lo anterior implica nuevos retos para la reflexión antropológica que incluyen a los propios sujetos antes objeto de estudio que se convierten en portavoces de sus propias experiencias:

Considero que la antropología social, cultural de corte colonial ha padecido de una permanente crisis de identidad, sobre todo con el surgimiento de la antropología compartida como una ciencia en manos de los propios indígenas y por su práctica dentro del propio grupo étnico. Esto a mi entender, llevaría a cada unidad étnica a la recuperación de su propia historia y permitiría que el objeto del estudio y de reflexión fuera por parte del propio grupo étnico, para diseñar así su propio proyecto de vida y de desarrollo, valiéndose del conocimiento que las ciencias les proporcionan. (Nahamad, 1978, p. 105)

Indio, concebido como sujeto de representación por la antropología mexicana, en palabras de Bonfil Batalla (1972), ya es una categoría colonial que establece relaciones de subordinación, explotación y dominio colonial. Es una generalización abstracta que pretende homogeneizar la diversidad. Es una imposición de la subjetividad porque trastoca las formas en que los individuos se conciben a sí mismos 
y los coloca en una cartografia del poder racializada y jerárquica. Pensar en la descolonización de la antropología entonces, como propone Aída Hernández (2012), es descolonizar la propia concepción de lo indígena, des-esencializar y restituir a los sujetos de sus capacidades de enunciar su propio ser.

\section{Conclusiones}

La emergencia de los movimientos indígenas en América Latina ha llevado a la necesidad de reconceptualizar el tema de lo indio, no solo -y en muchos de los casos- de maneras más complejas y desde vertientes distintas de la antropología. El tema de la modernidad entendida como proyecto civilizatorio unívoco y la crítica a esta pretendida universalidad, debate sobre la existencia de modernidades alternativas que se gestaron en paralelo al desarrollo de la modernidad capitalista y hegemónica. Desde esa lectura crítica de la modernidad, las comunidades indigenas y sus formas de sociabilidad no son interpretadas como formas pre-modernas, arcaicas o incivilizadas sino como matrices culturales que lograron pervivir al acontecimiento de la colonia, aunque trastocadas.

Comenzamos este ensayo preguntándonos si se ha registrado en la antropología mexicana un giro descolonizador o un viraje teóricoconceptual que reconfigure de manera sustancial las formas en que se ha pensado al y lo indígena. Después de hacer un breve recorrido histórico, podemos puntear las siguientes ideas como acercamientos e hipótesis para desarrollar en estudios posteriores:

- La relación de las ciencias sociales con el Estado mexicano asumió una connotación particular debido al proyecto totalizante que impulsó el Estado mexicano pos-revolucionario, con lo cual el paternalismo y el asistencialismo hacia lo indígena caracterizaron las políticas instrumentadas con el fin de incorporar al indígena a la Nación. Sin embargo, esa incorporación pasaba por procesos de aculturación que en muchos sentidos fueron violentos y nunca lograron integrar al indígena por completo.

- El reconocimiento del origen perverso de la disciplina, al ser una empresa de conocimiento de lo otro que inicia con los relatos de los cronistas españoles durante los primeros años de la colonia, tiene su momento de mayor desarrollo en el México pos-revolucionario, cuando el estado mexicano asume la tarea de mestizar al indigena 
para incorporarlo a la lógica de la Nación moderna. Más aún, al indigena se lo percibe como un problema, un desajuste e incluso, una traba al desarrollo y la modernización que el país necesita. De ahí su necesaria incorporación, lo cual implica la pérdida de su identidad, de su especificidad cultural, de su historia y de su proyecto civilizatorio.

- Como dice Esteban Krotz (2009): "El movimiento del 68 trajo consigo una poderosa crítica y una denuncia de la antropología colonizada y del indigenismo como instrumento de los designios de la burguesía gobernante". De ahí en adelante, la reconsideración que haga la antropología será en función de las prácticas de los propios sujetos coloniales. Por ello considero que más que hacer un ejercicio descolonizador, la antropologia mexicana ha diversificado las formas en las que asume lo indígena a partir de la mirada de los propios sujetos.

- La forma en que se ha visto al indio en México se encuentra cimentada en las concepciones formuladas en México pos-revolucionario, sin embargo, su origen es el momento colonial. El proyecto del mestizaje como vehículo de transformación de la Nación para su pleno acceso a la modernidad a través de la educación monocultural y monolingüe no ha logrado incorporar de lleno al indígena y cuando lo ha hecho, ha sido mediado por la violencia o el despojo. El fracaso de dichas politicas se relaciona con una estructura de dominación jerárquica y vertical, paternalista y asistencialista que niega, invisibiliza o desconoce a los indios que pretende incorporar a la Nación.

- El arribo del debate poscolonial en la década de 1990 a México coincidió con el levantamiento zapatista y la crisis del marxismo. Su discusión fue desplazada por ser considerado una vertiente de la posmodernidad, lo cual derivó en un rechazo a sus formulaciones. Recientemente se ha comenzado a estudiar su potencial analítico y explicativo de las sociedades colonizadas.

- La antropología mexicana tuvo una vertiente crítica que compartió la tesis del colonialismo interno que planteara Pablo González Casanova a finales de la década de 1970. Guillermo Bonfil fue el antropólogo que más desarrolló esta perspectiva para el caso de la antropología.

- Actualmente el debate poscolonial comienza a tener cierta presencia sobre todo en autores que mantienen una postura crítica y abrevan 
de otras tradiciones, como es el caso de Aída Hernández o Roger Magazine. Sin embargo, la descolonización de la antropología no puede ser vista solamente como un proyecto académico o teórico, la descolonización debe ser un complejo proceso que transforme las relaciones sociales, las estructuras de dominación y nuestros propios marcos de conocimiento. La descolonización de la antropología debe ir acompañada de la descolonización de la sociedad.

\section{Referencias}

Bidaseca, K. (2010) Perturbando el texto colonial. Los estudios (pos) coloniales en América Latina, Buenos Aires: Editorial SB.

Bonfil, G. (1970). Del indigenismo de la revolución a la antropología crítica. En Warman, Nolasco, Olivera y Valencia. De eso que llaman antropología mexicana (pp. 39-61). México: Nuestro Tiempo.

Bonfil, G. (1972). El concepto de indio en América. Una categoría de la situación colonial. Anales de Antropología, 9, 110.

Bonfil, G. (1995). Obras escogidas, Tomo IV, México: Instituto Nacional Indigenista.

Bonfil, G. (2006. México profundo. Una civilización negada, México: Editorial Debolsillo.

Castellanos, A., López y Rivas, G. (1992). El reconocimiento constitucional de los pueblos indios de México. Nueva Antropología, XII (42).

CEDOZ. (2013). Centro de documentación sobre zapatismo. Recuperado el 8 de septiembre de 2013 de http://www.cedoz.org/site/content.php?doc=400

Echeverría, B. (1998). La modernidad de lo barroco. México: Era.

Germani, G. (1971). Politica y sociedad en una época en transición: de la sociedad tradicional a la sociedad de masas, Buenos Aires: Paidos.

Gilroy, P. (2001). O Atlantico negro. Modernidade e dupla consciencia. Sao Paulo: Ed. 34.

González, P. (2006), Sociología de la explotación, Buenos Aires: CLACSO.

Grigulevich, J. (1976, julio). ¿Cuál es el futuro de la Antropología Social?. Nueva Antropología, 2 (5) 7-28.

Hernández, R. (2012). Sur profundo. Identidades indigenas en la frontera Chiapas-Guatemala, México: Centro de Investigaciones y Estudios Superiores en Antropología Social, Comisión Nacional para el Desarrollo de los Pueblos Indigenas. 
Krotz, E. (2009), La antropología mexicana y su búsqueda permanente de identidad. En G. Lins Ribeiro y Escobar, A. (Eds.). Antropologias del mundo. Transformaciones disciplinarias dentro de sistemas de poder. México: CIESASUAM-Ibero-The Wenner Gren Foundation-Envisión.

Lenkersdorf, C. (2002). Filosofar en clave tojolabal, México: Miguel Ángel Porrua. Marcos, S. (2011). Mujeres indigenas, rebeldes, zapatistas, México: Ediciones Eón. Medina, A. (1976). Ortodoxia y herejía en la antropología mexicana. Anales de Antropologia, 13 (1), 217-231. Recuperada el 3 de septiembre de 2012 de http:// revistas.unam.mx/index.php/antropologia/article/view/327

Medina, A. (1987). El etnopopulismo y la cuestión nacional en México: el espacio político de los grupos étnicos. Anales de Antropología, 24 (1), 171-198. Recuperada de http:/ /www.revistas.unam.mx/index.php/antropologia/article/ view/ 10003

Mellino, M. (2008). La crítica posocolonial. Descolonización, capitalismo y cosmopolitismo en los estudios poscoloniales, Buenos Aires: Paidos.

Mignolo (2007). El pensamiento decolonial: desprendimiento y apertura. Un Manifiesto. En Castro-Gómez y Grosfoguel (Eds). El giro decolonial: reflexiones para una diversidad epistémica más allá del capitalismo global (pp. 25-46). Bogotá: Pontificia Universidad Javeriana, Universidad Central y Siglo del Hombre Editores.

Nahmad, S. (1978). Perspectivas y proyección de la antropología aplicada en México. Nueva Antropología, III (9).

Nahamad, S. (2011). El papel de la antropología en los cambios y retos del siglo XXI. $71^{\text {ava }}$ Reunión anual de la Sociedad de Antropología Aplicada. Marzo 29 a abril 2, Seattle. Recuperado el 24 de octubre de 2012 de http:/ / salomonnahmad. files.wordpress.com/2011/04/nahmad-sfaa-2011-espac3b1ol.pdf

Quijano, A. (1992). Colonialidad y modernidad-racionalidad. Perú Indígena, 13 (29), 11-20. Recuperado el 25 de mayo de 2013 de http://es.scribd.com/ doc/70586547/Quijano-Colonialidad-y-Modernidad-1992

Quijano, A. (2000). Colonialidad del poder, eurocentrismo y América Latina. En E. Lander. La Colonialidad del saber, eurocentrismo y ciencias sociales en América Latina, perspectivas latinoamericanas (pp. 201-246). Buenos Aires: CLACSO-UNESCO.

Rivera, S. (1993). La raíz: colonizadores y colonizados. En Albo, J. y Barrios, R. (Coords.). Violencias encubiertas en Bolivia. Cultura y politica (pp. 27-139). La Paz: CIPCA, Aruwiyiri.

Robichaux, D. y Magazine, R. ( 2007). Las limitaciones de las categorias de lo 'indigena' y 'mestizo' en los estudios rurales de México. En Sesia, P. y Sarmiento, S. El cambio en la sociedad rural mexicana ¿se valoran los recursos estratégicos? Volumen II. Pueblos indigenas, territorio y género en el México rural contemporáneo (pp.190-209). México: AMER-JP-UAM-CONACYT-UAEM-UMSNH. 
Rolph-Trouillot, M. (2011). Modernidad de otro modo. Lecciones caribeñas desde el lugar del salvaje. Tábula Rasa, 14, 79-97. Recuperado el 12 de junio de 2013 de http://www.scielo.org.co/pdf/tara/n14/n14a04.pdf

Rozat, G. (2001). Los origenes de la Nación. Pasado indigena e historia nacional. México: Universidad Iberoamericana.

Segato, R. (2007). La Nación y sus Otros. Raza, etnicidad y diversidad religiosa en tiempos de Politicas de la Identidad. Buenos Aires: Prometeo.

Stavenhagen, R. (1977). Clases, colonialismo y aculturación; ensayo sobre un sistema de relaciones interétnicas en Mesoamérica. Guatemala: Cuadernos del seminario de integración social guatemalteca, 19.

Warman, A. (1970). Todos santos y todos difuntos. Crítica histórica de la antropología mexicana. En Warman, Nolasco, Bonfil, Olivera y Valencia. De eso que llaman antropología mexicana (pp. 9-38). México: Nuestro Tiempo.

Warman, A., Nolasco, M., Bonfil, G., Olivera, M., y Valencia, E. (1970). De eso que llaman antropología mexicana. México: Nuestro Tiempo. 